\title{
Endocervical Biopsy
}

National Cancer Institute

\section{Source}

National Cancer Institute. Endocervical Biopsy. NCI Thesaurus. Code C51629.

Removal of tissue from the endocervix for microscopic examination. 